\title{
DFT Calculations for Corrosion Inhibition of Ferrous Alloys by Pyrazolopyrimidine Derivatives
}

\author{
Nuha Ahmed Wazzan ${ }^{1 *}$, Fatma Mohamed Mahgoub ${ }^{1,2}$ \\ ${ }^{1}$ Chemistry Department, Faculty of Science, King Abdul-Aziz University, Jeddah, KSA \\ ${ }^{2}$ Institute of Graduate Studies and Research, University of Alexandria, Alexandria, Egypt \\ Email: *nwazzan@kau.edu.sa
}

Received December 25, 2013; revised January 18, 2014; accepted January 25, 2014

Copyright (c) 2014 Nuha Ahmed Wazzan, Fatma Mohamed Mahgoub. This is an open access article distributed under the Creative Commons Attribution License, which permits unrestricted use, distribution, and reproduction in any medium, provided the original work is properly cited. In accordance of the Creative Commons Attribution License all Copyrights (C) 2014 are reserved for SCIRP and the owner of the intellectual property Nuha Ahmed Wazzan, Fatma Mohamed Mahgoub. All Copyright (C) 2014 are guarded by law and by SCIRP as a guardian.

\section{ABSTRACT}

The inhibition performance of 5-tolyl-2-phenylpyrazolo[1,5-c] pyrimidine-7(6H)thione (Tolyl), 5-tolyl-2-pheenylpyrazolo [1,5-c]pyrimidine-7(6H)one (Inon) was investigated as corrosion inhibitors using density functional theory (DFT) at the B3LYP/6-31 + G(d,p) level of theory. The calculated quantum chemical parameters correlated to the inhibition efficiency are: the highest occupied molecular orbital energy ( $E_{\text {номо }}$ ), the lowest unoccupied molecular orbital energy ( $\left.E_{L U M O}\right)$, the energy gap $\left(\Delta E_{L-H}\right)$, dipole moment $(\mu)$, ionization energy ( $I$ ), electron affinity $(A)$, absolute electronegativity $(\chi)$, absolute hardness $(\eta)$, absolute softness $(\sigma)$, the fraction of electron transferred $(\Delta N)$, and the total energy $\left(E_{t o t}\right)$ which were calculated. The local reactivity has been analyzed through the Fukui function and local softness indices in order to compare the possible sites for nucleophilic and electrophilic attacks. The success of DFT calculations in predicting the inhibition efficiency was assessed.

\section{KEYWORDS}

\section{Pyrazolopyrimidine Derivative; Corrosion Inhibitors; Adsorption; DFT Calculations; Fukui Function}

\section{Introduction}

Corrosion of metals is a major industrial problem that has attracted many investigation and researches. The use of inhibitors is one of the most practical methods to protect metals against corrosion. Most efficient inhibitors are organic compounds containing electronegative functional groups and $\pi$-electrons in triple or conjugated double bonds. Researchers conclude that the adsorption on the metal surface depends mainly on the physicochemical properties of the inhibitor group, such as the functional group, molecular electronic structure, electronic density at the donor atom, $\pi$-orbital character and the molecular size [1-3]. A number of heterocyclic compounds containing nitrogen, oxygen, and sulphur either in the aromatic or long chain carbon system have been reported to be effective inhibitors [4,5]. The inhibition efficiency has been

*Corresponding author. closely related to the inhibitor adsorption abilities and the molecular properties for different kinds of organic compounds [6,7]. Organic compounds, which can donate electrons to unoccupied $d$-orbital of metal surface to form coordinate covalent bonds and can also accept free electrons from the metal surface by using their anti-bonding orbital to form feedback bonds, constitute excellent corrosion inhibitors $[8,9]$.

A lot of work on heterocyclic inhibitors has been studied experimentally [10-14]. On the other hand, many reported theoretical studies in order to correlate between structural and electronic parameters and the inhibition efficiency [6,8,15-19]. The results from these researches have been used to interpret very well many experimental phenomena.

Density functional theory (DFT) [20,21] following the approach of Kohn and Sham has proven to be an important tool in modern quantum chemistry because of its 
ability to include some effects of electron correlation at a greatly reduced computational cost [22-24]. Recently, DFT methods have been used to analyze the characteristics of the inhibitor/surface mechanism and to describe the structural nature of the inhibitor in corrosion process [6,25-28].

The object of the present paper is to carry out a DFT calculations on the electronic parameters of two pyrazolo[1,5-c]pyrimidine derivatives and they are:

5-tolyl-2-phenylpyrazolo[1,5-c]pyrimidine-7(6H)thion e (Tolyl)

5-tolyl-2-phenylpyrazolo[1,5-c]pyrimidine-7(6H)one (Inon)

used as inhibitors, and to determine a relationship between some quantum chemical parameters obtained from the structure of the compounds and the inhibition efficiencies of corrosion of ferrous alloys obtained experimentally by Mahgoub et al. [12]. The chemical structures of the studied inhibitors are shown in Figure 1.

Computational calculations were obtained by means of DFT/B3LYP/6-31 + G(d,p) level of theory. Parameters such as $E_{\text {номо }}, E_{L U M O}$, energy gap $\left(\Delta E_{L-H}\right)$, dipole moment $(\mu)$, ionization energy $(I)$, electron affinity $(A)$, absolute electronegativity $(\chi)$, absolute hardness $(\eta)$, absolute softness $(\sigma)$, the fraction of electron transferred $(\Delta N)$, and the total energy $\left(E_{t o t}\right)$ were calculated. The local reactivity has been analyzed by means of the Fukui indices, since they indicate the reactive region, in the form of the nucleophilic and electrophilic behavior of each atom in the molecule.

\section{DFT Calculations}

The present calculations were performed using Gaussian<smiles>Cc1ccc(-c2cc3cc(-c4ccccc4)nn3c(=S)[nH]2)cc1</smiles>

(a)<smiles>Cc1ccc(-c2cc3cc(-c4ccccc4)nn3c(=O)[nH]2)cc1</smiles>

(b)

Figure 1. The molecular structures of the investigated inhibitors: (a) 5-tolyl-2-phenylpyrazolo [1,5-c] pyrimidine7(6H) thione (Tolyl), (b) 5-tolyl-2-phenylpyrazolo [1,5-c] pyrimidine-7(6H)one (Inon).
09 program package [29]. Geometry optimizations were conducted by DFT using Becke's three parameter exchange functional (B3) [30], and includes a mixture of HF with DFT exchange terms associated with the gradient corrected correlation functional of Lee, Yang, and Parr (LYP) [31] and the 6-31 + G(d,p) basis set.

In geometry optimizations every bond length, bond angle and dihedral angle was allowed to relax, free of constraints. The nature of the stationary points was confirmed by vibrational frequency analysis, to verify that only real frequencies values (i.e. no imaginary frequency) were obtained for all geometries. In order to calculate the Fukui functions, the electron populations for neutral Tolyl, Tolyl cation, Tolyl anion, neutral Inon, Inon cation, and Inon anion species were calculated (using: the keyword Pop = Full). For the ionic forms, the calculations were performed at the optimized geometries of the neutral forms (using: single point energy calculation; charge $= \pm 1$; and multiplicity $=$ Doublet). This avoids the problem of trying to do a geometry optimization on a species that may not be a stationary point on the potential energy surface.

Frontier molecular orbitals; highest occupied molecular orbital (HOMO) and lowest unoccupied molecular orbital (LUMO) was used to predict the adsorption centers of the inhibitor molecule. For the simplest transfer of electrons, adsorption should occur at the part of the molecule where the softness, $\sigma$, which is a local property, has the highest value. According to Koopman's theorem [32], the energies of the HOMO and the LUMO orbitals of the inhibitor molecule are related to the ionization potential, $I$, and the electron affinity, $A$, respectively, by the following relationships:

$$
\begin{aligned}
& I=-E_{\text {номо }} \\
& A=-E_{\text {LUMO }}
\end{aligned}
$$

Absolute electronegativity, $\chi$, and absolute hardness, $\eta$, of the inhibitor molecule are given [33]:

$$
\begin{aligned}
& \chi=\frac{I+A}{2} \\
& \eta=\frac{I-A}{2}
\end{aligned}
$$

The softness is the inverse of the hardness [33]:

$$
\sigma=\frac{1}{\eta}
$$

Electronegativity, hardness, and softness have proved to be very useful quantities in chemical reactivity theory. When two systems, Fe and inhibitor, are brought together, electrons will flow from lower $\chi$ (inhibitor) to higher $\chi(\mathrm{Fe})$, until the chemical potentials become equal.

The number of transferred electrons $(\Delta N)$ was also 
calculated by using the equation below [32]:

$$
\Delta N=\frac{\chi_{F e}-\chi_{i n h}}{2\left(\eta_{F e}+\eta_{i n h}\right)}
$$

where $\chi_{\mathrm{Fe}}$ and $\chi_{\text {inh }}$ denote the absolute electronegativity of iron and inhibitor molecule, respectively, $\eta_{\mathrm{Fe}}$ and $\eta_{\text {inh }}$ denote the absolute hardness of iron and the inhibitor molecule, respectively.

In this study, we use the theoretical value of $\chi_{\mathrm{Fe}}=7 \mathrm{eV} / \mathrm{mol}$ and $\eta_{\mathrm{Fe}}=0 \mathrm{eV} / \mathrm{mol}$ for the computation of number of transferred electrons [32]. The absolute electrophilicity index is given by [34]:

$$
\omega=\frac{\mu^{2}}{2 \eta}
$$

According to the definition, this index measures the tendency of chemical species to accept electrons. More reactive nucleophile is characterized by lower value of $\mu$, and $\omega$; and conversely more reactive electrophile is characterized by a higher value of $\mu$, and $\omega$. This new reactivity index measures the stabilization in energy when the system acquires an additional electronic charge $\Delta N$ from the environment.

\section{Results and Discussion}

\subsection{Experimental Findings [12]}

F. M. Mahgoub et al. investigated experimentally the inhibition of corrosion of ferrous alloys using a group of pyrazolo [1,5-c] pyrimidine as corrosion inhibitors. Using electrochemical measurements and corrosion tests such as Tafel extrapolation and linear polarization resistance techniques they indicated clearly a decrease in the corrosion rate in the presence of Tolyl and Inon inhibitors. The inhibition efficiencies of the Tolyl compound are markedly higher than that of the Inon compound (Table 1).

\subsection{Theoretical Findings}

Figure 2 shows the optimized structures of Tolyl and Inon inhibitors along with atomic numbering. For Tolyl and Inon molecules, the computed quantum chemical properties such as $E_{\text {номо }}, E_{L U M O}, \Delta E_{L-H}$, and dipole moment $(\mu)$ are given in Table 2 .

Frontier molecular orbital (FMO): The interaction between the inhibitor and the metal is through the donation of the electrons from the inhibitor occupied orbitals (mainly from the HOMO) to the $d$-orbital of the metal [27], and also through the acceptance of the electrons from the $d$-orbital of the metal to the unoccupied orbitals (mainly to the LUMO) of the inhibitor. Thus, $E_{\text {номо }}$ measures the tendency of donating electron by a molecule [35]. Therefore, higher value of $E_{\text {номо indicates }}$ better tendency of donating electron, and enhancing the
Table 1. Corrosion rate and the protection efficiency (\%P) of $0.01 \mathrm{M}$ of pyrazolo [1,5-c] pyrimidine inhibitors from Tafel and linear polarization plots for carbon steel in stagnant cooling water $\left(200 \mathrm{ppm} \mathrm{Cl}^{-}\right)$at $25^{\circ} \mathrm{C}$ [12].

\begin{tabular}{ccccc}
\hline Inhibitor & \multicolumn{2}{c}{ Tafel extrapolation } & \multicolumn{2}{c}{ Linear polarization } \\
\hline & Rate (mpy) & $\% \mathrm{P}$ & $R_{p}^{-1}\left(\Omega^{-1} \mathrm{~cm}^{-2}\right)$ & $\% \mathrm{P}$ \\
Blank & 10.34 & - & 1.16 & - \\
Tolyl & 0.68 & 93.42 & 0.07 & 93.97 \\
Inon & 4.64 & 55.18 & 0.58 & 49.14 \\
\hline
\end{tabular}

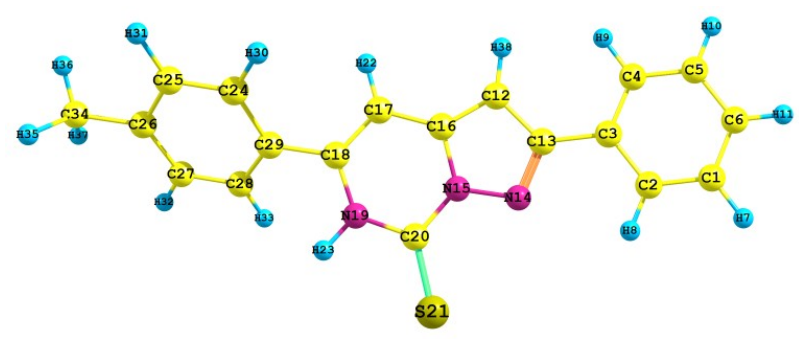

(a)

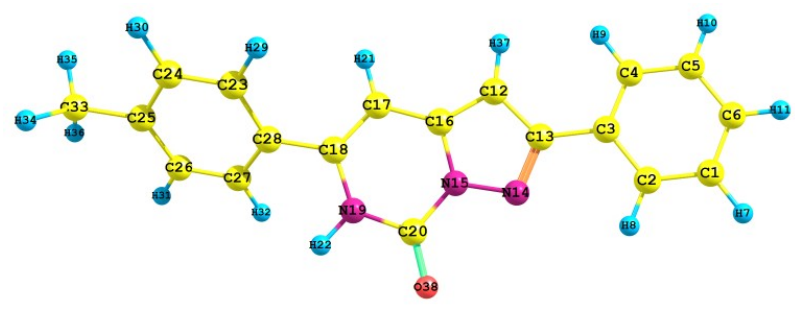

(b)

Figure 2. Optimized geometries of (a) Tolyl and (b) Inon molecules along with atomic numbering calculated at B3LYP/6-31 + G(d, p) level of theory.

Table 2. Calculated quantum chemical parameters of Tolyl and Inon molecules calculated at B3LYP/6-31 + G(d,p) level of theory.

\begin{tabular}{cccc}
\hline Quantum parameters & Unit & Tolyl & Inon \\
\hline$E_{\text {номо }}$ & $(\mathrm{eV})$ & -0.21463 & -0.21943 \\
$E_{\text {LUмо }}$ & $(\mathrm{eV})$ & -0.06821 & -0.06535 \\
$\Delta E_{L-H}$ & $(\mathrm{eV})$ & 0.14642 & 0.15408 \\
$\mu$ & (debye) & 7.2231 & 6.8992 \\
\hline
\end{tabular}

adsorption of the inhibitor on the metal surface and therefore better inhibition efficiency. On the other hand, $E_{L U M O}$ indicates the ability of the molecule to accept electrons, therefore, lower value of $E_{L U M O}$ indicates better ability to accept electrons, and also this will enhance the adsorption of the inhibitor on the metal surface and therefore better inhibition efficiency. The binding ability of the inhibitor to the metal surface increases with increasing of the HOMO and decreasing of the LUMO energy values. Frontier molecular orbital diagrams of Tolyl and Inon is shown in Figure 3. From Table 2, the highest value of $L U M O-0.21463 \mathrm{eV}$ of 


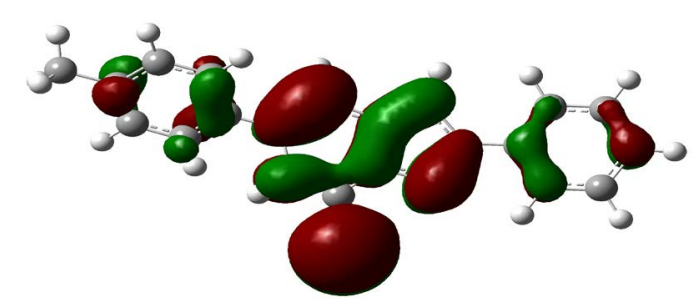

HOMO

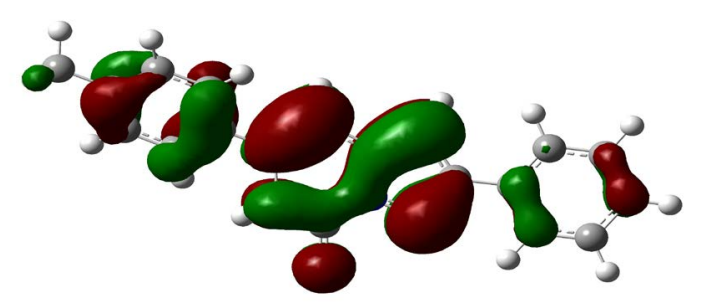

Tolyl

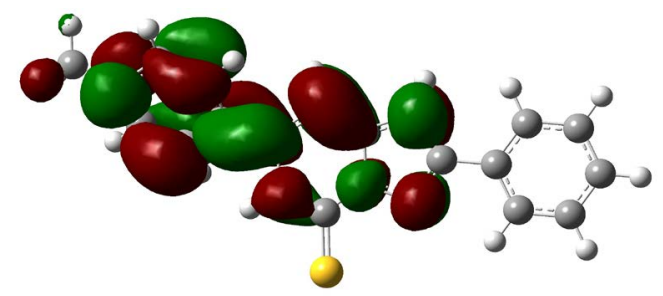

LUMO

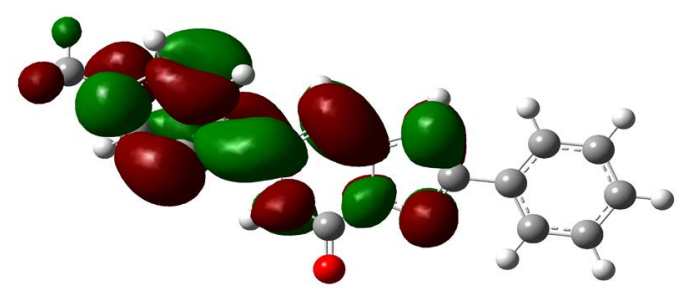

Figure 3. Frontier molecular orbitals (FMO) of Tolyl and Inon molecules calculated at B3LYP/6-31 + G(d,p) level of theory.

Tolyl compared to that of Inon $-0.21943 \mathrm{eV}$, also the lowest value of $E_{\text {LUMO }}-0.06821 \mathrm{eV}$ of Tolyl compared to that of Inon $-0.06535 \mathrm{eV}$ indicates the better inhibition efficiency of Tolyl, a result which is in total a agreement with the experimental finding.

The energy gap ( $\left.\Delta E_{L-H}=E_{L U M O}-E_{\text {НОMO }}\right)$ is an important parameter as a function of reactivity of the inhibitor molecule towards the adsorption on the metal surface. As $\Delta E_{L-H}$ decreases the reactivity of the molecule increases leading to better inhibition efficiency [28]. Table 2 shows that Tolyl inhibitor has the lowest energy gap $0.14642 \mathrm{eV}$ compared to of Inon inhibitor 0.15408 $\mathrm{eV}$, with a difference equals $0.0077 \mathrm{eV}$; this means that Tolyl molecule could have better performance as carrion inhibitor than Inon molecule, a conclusion which is in total agreement with the experimental finding.

Dipole moment: The dipole moment $(\mu)$ is another important electronic parameter that result from non-uniform distribution of charges on the various atoms in the molecule. The high value of dipole moment probably increases the adsorption between the inhibitor and the metal surface [36]. The energy of the deformability increases with the increase in $\mu$, making the molecule easier to adsorb at the ferrous surface. In addition, the volume of the inhibitor molecules also increases with the increase of $\mu$, this increase the contact area between the molecule and the surface of iron and increasing the corrosion inhibition ability of the inhibitor. In our study, the value 7.2231 Debye of Tolyl indicates its better inhibition efficiency compared to 6.8992 Debye of Inon which totally agrees with the experimental findings (Table 2).

Other computed quantum chemical properties such as ionization energy $(I)$, electron affinity $(A)$, absolute electronegativity $(\chi)$, absolute hardness $(\eta)$, absolute softness $(\sigma)$, absolute electrophilicity ( $\omega)$, the fraction of electron transferred $(\Delta N)$, and the total energy $\left(E_{\text {tot }}\right)$ for Tolyl and Inon inhibitors are given in Table 3.

Ionization energy: Ionization energy $(I)$ is a fundamental descriptor of the chemical reactivity of a toms and molecules. High ionization energy indicates high stability and chemical inertness and vice versa [37]. The low ionization energy $0.21463 \mathrm{eV}$ of Tolyl indicates its high inhibition efficiency compared to $0.21943 \mathrm{eV}$ of Inon which totally agrees with the experimental findings (Table 3 ).

Electronegativity: Table 3 shows the order of electronegativity $(\chi)$ as Tolyl < Inon. Hence, an increase in the difference of electronegativity between the metal and the inhibitor is observed in the order Tolyl > Inon. According to Sanderson's electronegativity equalization principal [38], Inon with a high electronegativity and low difference of electronegativity quickly reaches equalization and hence low reactivity is expected which in turn indicates low inhibition efficiency, also conclusion in total agreement with the experimental finding.

Hardness and softness: Absolute hardness $(\eta)$ and softness $(\sigma)$ are important properties to measure the molecular stability and reactivity. It is apparent that the chemical hardness fundamentally signifies the resistance towards the deformation or polarization of the electron cloud of the atoms, ions, or molecules under small perturbation of chemical reaction. A hard molecule has a large energy gap (large $\Delta E_{L-H}$ value) and a soft molecule has a small energy gap (small $\Delta E_{L-H}$ value) [1]. In this study Tolyl with low hardness value $\eta=0.07321 \mathrm{eV}$ compared to that of the Inon $\eta=0.07704 \mathrm{eV}$ has a low energy gap. Normally, the inhibitor with the least value of absolute hardness (hence, the highest value of absolute softness) is expected to have the highest inhibition efficiency [39]. Tolyl with the softness value of $13.65934 \mathrm{eV}$ 
Table 3. Calculated quantum chemical parameters of Tolyl and Inon molecules calculated at B3LYP/6-31 + G(d,p) level of theory.

\begin{tabular}{|c|c|c|c|}
\hline $\begin{array}{l}\text { Quantum } \\
\text { parameters }\end{array}$ & Unit & Tolyl & Inon \\
\hline$I=-E_{\text {номо }}$ & (au) & 0.21463 & 0.21943 \\
\hline$A=-E_{L U M O}$ & (au) & 0.06821 & 0.06535 \\
\hline$\chi=\frac{I+A}{2}$ & (au) & 0.14142 & 0.14239 \\
\hline$\eta=\frac{I-A}{2}$ & (au) & 0.07321 & 0.07704 \\
\hline$\sigma=\frac{1}{\eta}$ & $\left(\mathrm{au}^{-1}\right)$ & 13.65934 & 12.98027 \\
\hline$\omega=\frac{\mu^{2}}{2 \eta}$ & (au) & 356.32546 & 308.92370 \\
\hline$\Delta N=\frac{\chi_{f e}-\chi_{n b}}{2\left(\eta_{f_{c e}}+\eta_{m b n}\right)}$ & & 46.84182 & 44.50681 \\
\hline$E_{\text {tot }}$ & (au) & -1295.56608 & -972.61603 \\
\hline
\end{tabular}

has the highest inhibition efficiency compared to $12.98027 \mathrm{eV}$ of Inon; this result is also in agreement with the experimental finding (Table 3 )

Number of electrons transferred: The number of electrons transferred ( $\Delta N$ ) was also calculated and tabulated in Table 3. If $\Delta N<3.6$, the inhibition efficiency increases by increasing the electron-donating ability of these inhibitors to donate electrons to the metal surface [40] and it increases in the following order: Tolyl > Inon. The results indicate that $\Delta N$ values correlate strongly with experimental inhibition efficiencies. Thus, the highest fraction of electron transferred is associated with the best inhibitor Tolyl ( $\Delta N=46.841$ ), while, the least fraction is associated with the inhibitor that has the least inhibition efficiency Inon ( $\Delta N=44.5068$ ).

Total energy: The total energy of Tolyl inhibitor is $E_{\text {tot }}=-1295.57$ a.u. , while for Inon inhibitor it is $E_{\text {tot }}=-972.62$ a.u. , hence, the difference in the total energies between the two inhibitors is $\Delta E_{\text {tot }}=322.95$ a.u. This result indicated that Tolyl inhibitor is favorably adsorbed through the active centers of adsorption on the ferrous surface (Table 3 ).

Local selectivity: The local selectivity of a corrosion inhibitor is best analyzed using the Fukui function [41, 42]. The Fukui indices permit the distinction of each part of a molecule on the basis of its chemical behavior due to different substituent functional groups. The Fukui function can be formally defined as:

$$
f(r)=\left(\frac{\delta \sigma}{\delta v}\right)_{N}
$$

where $v(r)$ indicates that the differentiation is carried out under constant external potentials, and the functional derivative must be taken at constant number of electron, $N$. If it is assumed that the total energy, $E$, is a function of $v(r)$ and is an exact differential, then the Maxwell relations between derivatives can be applied to derive the following equation:

$$
f(r)=\left(\frac{\delta \rho(r)}{\delta N}\right)_{v}
$$

where $\rho(r)$ is the electron density. Equation (9) is the most standard presentation of the Fukui function. The Fukui function is provoked by the fact that if an electron $\delta$ is transferred to an $N$ electron molecule, it will tend to distribute so as to minimize the energy of the resulting $N+\delta$ electron system. The resulting change in electron density is the nucleophilic $\left(f^{+}\right)$and electrophilic $\left(f^{-}\right)$Fukui functions, which can be calculated using the finite difference approximation as follows:

$$
\begin{gathered}
f^{+}=\left(\frac{\delta \rho(r)}{\delta N}\right)_{v}^{+}=\rho_{(N+1)}-\rho_{(N)} \\
f^{-}=\left(\frac{\delta \rho(r)}{\delta N}\right)_{v}^{+}=\rho_{(N)}-\rho_{(N-1)}
\end{gathered}
$$

where $\rho_{(N+1)}, \rho_{(N)}$, and $\rho_{(N-1)}$ are the electronic densities of anionic, neutral, and cationic forms of the atom with $N+1, N$, and $N-1$ electrons.

Calculated values of $\rho_{(N+1)}, \rho_{(N)}, \rho_{(N-1)}, f^{+}$, and $f^{-}$for Tolyl and Inon are presented in Tables 4 and 5. The $f^{+}$measures the changes of density when the molecule gain electron/s and it corresponds to reactivity with respect to nuecleophilic attack, thus, the site for nucleophilic attack is the site where the value of $f^{+}$is maximum. On the other hand, $f^{-}$corresponds to reactivity with respect to electrophilic attack or when the molecule loss electron/s, thus, the site for electrophilic attack is the site where the value of $f^{-}$is maximum. For the Tolyl inhibitor, Table 4, it can be deduced that the sites for nucleophilic attack is in the carbon atom (C13). However, the sites for electrophilic attack are in the carbon atoms (C26 and C29). For the Inon inhibitor, Table 5, the sites for nucleophilic attack is in the carbon atom (C3). However, the sites for electrophilic attack are in the carbon atoms (C13, C18, and C24).

The HOMO and LUMO orbitals of Tolyl and Inon, Figure 2, clearly reveal the information that governs the nucleophilic and electrophilic attacks on the studied inhibitors. The information obtained from the HOMO and LUMO orbitals are consistent with the findings obtained from the Fukui function. The FMO diagram of Tolyl and Inon indicates the lack of electron cloud in LUMO in C13 and C3 for Tolyl and Inon inhibitors, respectively, which is confirmed by the Fukui function $f^{+}$. In case of HOMO of Tolyl the dense electron cloud around (C26 and C29) indicates the site of electrophilic attack. The same is the case around (C13 and C18, and C24) in Inon as confirmed by the Fukui function $f^{-}$too.

The local softness, $\sigma^{+}$and $\sigma^{-}$, for an atom can be expressed as the product of the Fukui function, $f^{+}$and 
Table 4. Electron densities (ED), Fukui ( $f^{+} \& f^{-}$) and local softness ( $\left.\sigma^{+} \& \quad \sigma^{-}\right)$indices for nucleophilic and electrophilic attacks in Tolyl calculated at B3LYP/6-31 + G(d,p) level of theory.

\begin{tabular}{|c|c|c|c|c|c|c|c|c|}
\hline & & & ED & & & & & \\
\hline Nun & Atom & Tolyl & Tolyl cation & Tolyl anion & $f^{+}$ & $f^{-}$ & $\sigma^{+}$ & $\sigma^{-}$ \\
\hline 1 & $\mathrm{C}$ & 6.33398 & 6.31939 & 6.34772 & -0.01459 & -0.01374 & -0.19934 & -0.18764 \\
\hline 2 & $\mathrm{C}$ & 5.54040 & 5.51512 & 5.56286 & -0.02528 & -0.02246 & -0.34534 & -0.30679 \\
\hline 3 & $\mathrm{C}$ & 5.54462 & 5.53868 & 5.52984 & -0.00594 & 0.01478 & -0.08115 & 0.20191 \\
\hline 4 & $\mathrm{C}$ & 6.92758 & 6.90721 & 6.97282 & -0.02037 & -0.04524 & -0.27819 & -0.61800 \\
\hline 5 & $\mathrm{C}$ & 5.99172 & 5.97977 & 5.98440 & -0.01195 & 0.00731 & -0.16323 & 0.09988 \\
\hline 6 & $\mathrm{C}$ & 6.23699 & 6.20135 & 6.27367 & -0.03563 & -0.03668 & -0.48671 & -0.50105 \\
\hline 7 & $\mathrm{H}$ & 0.87125 & 0.84445 & 0.89345 & -0.02680 & -0.02220 & -0.36611 & -0.30322 \\
\hline 8 & $\mathrm{H}$ & 0.84957 & 0.84385 & 0.85498 & -0.00572 & -0.00541 & -0.07809 & -0.07390 \\
\hline 9 & $\mathrm{H}$ & 0.89016 & 0.87631 & 0.89562 & -0.01385 & -0.00546 & -0.18917 & -0.07459 \\
\hline 10 & $\mathrm{H}$ & 0.87536 & 0.84599 & 0.89762 & -0.02937 & -0.02225 & -0.40112 & -0.30399 \\
\hline 11 & $\mathrm{H}$ & 0.87577 & 0.84272 & 0.90166 & -0.03304 & -0.02589 & -0.45136 & -0.35364 \\
\hline 12 & $\mathrm{C}$ & 6.43052 & 6.37145 & 6.47589 & -0.05907 & -0.04537 & -0.80687 & -0.61975 \\
\hline 13 & C & 6.10110 & 6.12200 & 6.10673 & 0.02090 & -0.00563 & 0.28547 & -0.07696 \\
\hline 14 & $\mathrm{~N}$ & 6.89364 & 6.79874 & 6.94713 & -0.09490 & -0.05348 & -1.29633 & -0.73054 \\
\hline 15 & $\mathrm{~N}$ & 7.19098 & 7.18885 & 7.18557 & -0.00213 & 0.00541 & -0.02912 & 0.07384 \\
\hline 16 & $\mathrm{C}$ & 5.60464 & 5.60811 & 5.58073 & 0.00348 & 0.02391 & 0.04747 & 0.32653 \\
\hline 17 & $\mathrm{C}$ & 6.47492 & 6.42911 & 6.58500 & -0.04581 & -0.11008 & -0.62568 & -1.50367 \\
\hline 18 & $\mathrm{C}$ & 6.03984 & 6.06692 & 6.02122 & 0.02708 & 0.01862 & 0.36995 & 0.25435 \\
\hline 19 & $\mathrm{~N}$ & 7.21726 & 7.18203 & 7.22500 & -0.03523 & -0.00774 & -0.48123 & -0.10572 \\
\hline 20 & $\mathrm{C}$ & 6.00237 & 6.00231 & 5.98891 & -0.00006 & 0.01346 & -0.00083 & 0.18380 \\
\hline 21 & S & 15.96047 & 15.71851 & 16.13916 & -0.24195 & -0.17869 & -3.30493 & -2.44076 \\
\hline 22 & $\mathrm{H}$ & 0.85908 & 0.81829 & 0.89273 & -0.04080 & -0.03365 & -0.55723 & -0.45958 \\
\hline 23 & $\mathrm{H}$ & 0.65587 & 0.63561 & 0.66894 & -0.02026 & -0.01307 & -0.27678 & -0.17847 \\
\hline 24 & $\mathrm{C}$ & 6.07829 & 6.04636 & 6.16478 & -0.03193 & -0.08649 & -0.43616 & -1.18138 \\
\hline 25 & $\mathrm{C}$ & 6.37156 & 6.39077 & 6.37024 & 0.01921 & 0.00132 & 0.26235 & 0.01798 \\
\hline 26 & C & 5.62244 & 5.63637 & 5.57685 & 0.01393 & 0.04559 & 0.19032 & 0.62277 \\
\hline 27 & $\mathrm{C}$ & 6.35166 & 6.35592 & 6.34190 & 0.00426 & 0.00975 & 0.05826 & 0.13321 \\
\hline 28 & $\mathrm{C}$ & 5.87439 & 5.85395 & 6.00482 & -0.02044 & -0.13043 & -0.27918 & -1.78153 \\
\hline 29 & C & 5.94625 & 5.89363 & 5.90040 & -0.05262 & 0.04584 & -0.71870 & 0.62618 \\
\hline 30 & $\mathrm{H}$ & 0.87185 & 0.86148 & 0.89349 & -0.01037 & -0.02164 & -0.14166 & -0.29559 \\
\hline 31 & $\mathrm{H}$ & 0.87321 & 0.84698 & 0.90811 & -0.02623 & -0.03490 & -0.35822 & -0.47677 \\
\hline 32 & $\mathrm{H}$ & 0.87185 & 0.84627 & 0.90686 & -0.02557 & -0.03501 & -0.34931 & -0.47824 \\
\hline 33 & $\mathrm{H}$ & 0.86580 & 0.85693 & 0.89175 & -0.00888 & -0.02594 & -0.12123 & -0.35438 \\
\hline 34 & $\mathrm{C}$ & 6.52846 & 6.46631 & 6.63098 & -0.06214 & -0.10252 & -0.84883 & -1.40037 \\
\hline 35 & $\mathrm{H}$ & 0.82687 & 0.80634 & 0.85547 & -0.02053 & -0.02860 & -0.28040 & -0.39064 \\
\hline 36 & $\mathrm{H}$ & 0.84175 & 0.82543 & 0.86397 & -0.01632 & -0.02222 & -0.22295 & -0.30352 \\
\hline 37 & $\mathrm{H}$ & 0.84228 & 0.82672 & 0.86405 & -0.01556 & -0.02177 & -0.21254 & -0.29732 \\
\hline 38 & $\mathrm{H}$ & 0.86531 & 0.82976 & 0.89470 & -0.03555 & -0.02939 & -0.48558 & -0.40145 \\
\hline
\end{tabular}

$f^{-}$, and the global softness, $\sigma$, as follows:

$$
\begin{aligned}
& \sigma^{+}=f^{+} \sigma \\
& \sigma^{-}=f^{-} \sigma
\end{aligned}
$$

The local softness contains information similar to those obtained from Fukui function plus additional information about the molecular softness, which is related to the global reactivity with respect to a reaction partner.
Calculated values of $\sigma^{+}$and $\sigma^{-}$are presented in Tables 4 and 5 . From the results obtained, the sites for electrophilic and nucleophilic attack in the studied molecules are not similar.

\section{Conclusion}

Using the DFT/B3LYP/6-31 + G(d,p) level of theory, the inhibition efficiency of two pyrazolo [1,5-c] pyrimidine 
Table 5. Electron densities (ED), Fukui ( $\left.f^{+} \& f^{-}\right)$and local softness $\left(\sigma^{+} \& \sigma^{-}\right)$indices for nucleophilic and electrophilic attacks in Inon calculated at B3LYP/6-31 + G(d,p) level of theory.

\begin{tabular}{|c|c|c|c|c|c|c|c|c|}
\hline & & & ED & & & & & \\
\hline Num & Atom & Inon & Inon cation & Inon anion & $f^{+}$ & $f^{-}$ & $\sigma^{+}$ & $\sigma^{-}$ \\
\hline 1 & $\mathrm{C}$ & 6.48916 & 6.47821 & 6.50282 & -0.01095 & -0.01366 & -0.14953 & -0.18664 \\
\hline 2 & $\mathrm{C}$ & 5.14570 & 5.09850 & 5.20861 & -0.04720 & -0.06291 & -0.64469 & -0.85935 \\
\hline 3 & C & 5.26178 & 5.26936 & 5.22846 & 0.00758 & 0.03333 & 0.10352 & 0.45521 \\
\hline 4 & $\mathrm{C}$ & 7.16667 & 7.15542 & 7.16149 & -0.01126 & 0.00518 & -0.15375 & 0.07080 \\
\hline 5 & $\mathrm{C}$ & 6.43465 & 6.41462 & 6.43607 & -0.02004 & -0.00142 & -0.27366 & -0.01938 \\
\hline 6 & $\mathrm{C}$ & 6.19026 & 6.15136 & 6.21677 & -0.03890 & -0.02651 & -0.53128 & -0.36207 \\
\hline 7 & $\mathrm{H}$ & 0.87250 & 0.84223 & 0.89376 & -0.03026 & -0.02126 & -0.41335 & -0.29041 \\
\hline 8 & $\mathrm{H}$ & 0.85120 & 0.83917 & 0.85431 & -0.01202 & -0.00311 & -0.16424 & -0.04249 \\
\hline 9 & $\mathrm{H}$ & 0.88906 & 0.87481 & 0.89209 & -0.01425 & -0.00303 & -0.19467 & -0.04136 \\
\hline 10 & $\mathrm{H}$ & 0.87597 & 0.84427 & 0.89721 & -0.03170 & -0.02124 & -0.43297 & -0.29015 \\
\hline 11 & $\mathrm{H}$ & 0.87670 & 0.84090 & 0.90115 & -0.03580 & -0.02445 & -0.48895 & -0.33393 \\
\hline 12 & $\mathrm{C}$ & 5.92305 & 5.84689 & 5.98639 & -0.07615 & -0.06334 & -1.04021 & -0.86524 \\
\hline 13 & C & 6.56156 & 6.59484 & 6.55563 & 0.03328 & 0.00593 & 0.45461 & 0.08101 \\
\hline 14 & $\mathrm{~N}$ & 6.90740 & 6.75315 & 7.01710 & -0.15424 & -0.10971 & -2.10683 & -1.49851 \\
\hline 15 & $\mathrm{~N}$ & 7.38381 & 7.40233 & 7.36453 & 0.01852 & 0.01928 & 0.25304 & 0.26334 \\
\hline 16 & $\mathrm{C}$ & 5.38587 & 5.37614 & 5.39313 & -0.00973 & -0.00726 & -0.13289 & -0.09924 \\
\hline 17 & $\mathrm{C}$ & 6.59363 & 6.54798 & 6.66084 & -0.04565 & -0.06721 & -0.62354 & -0.91803 \\
\hline 18 & C & 5.86054 & 5.88252 & 5.83060 & 0.02199 & 0.02993 & 0.30031 & 0.40889 \\
\hline 19 & $\mathrm{~N}$ & 7.41681 & 7.38267 & 7.45092 & -0.03414 & -0.03411 & -0.46634 & -0.46593 \\
\hline 20 & $\mathrm{C}$ & 5.32033 & 5.30466 & 5.34046 & -0.01568 & -0.02013 & -0.21412 & -0.27496 \\
\hline 21 & $\mathrm{H}$ & 0.86216 & 0.82024 & 0.89442 & -0.04192 & -0.03226 & -0.57261 & -0.44062 \\
\hline 22 & $\mathrm{H}$ & 0.66261 & 0.63714 & 0.68186 & -0.02546 & -0.01925 & -0.34781 & -0.26301 \\
\hline 23 & $\mathrm{C}$ & 6.23551 & 6.21534 & 6.32340 & -0.02017 & -0.08789 & -0.27550 & -1.20051 \\
\hline 24 & C & 6.23838 & 6.25339 & 6.25052 & 0.01501 & -0.01214 & 0.20503 & -0.16584 \\
\hline 25 & $\mathrm{C}$ & 5.64173 & 5.65178 & 5.58817 & 0.01005 & 0.05355 & 0.13733 & 0.73151 \\
\hline 26 & $\mathrm{C}$ & 6.45820 & 6.46157 & 6.45730 & 0.00337 & 0.00090 & 0.04606 & 0.01227 \\
\hline 27 & $\mathrm{C}$ & 5.71726 & 5.68002 & 5.86597 & -0.03724 & -0.14871 & -0.50866 & -2.03125 \\
\hline 28 & $\mathrm{C}$ & 5.89677 & 5.84612 & 5.85100 & -0.05065 & 0.04577 & -0.69180 & 0.62522 \\
\hline 29 & $\mathrm{H}$ & 0.87109 & 0.85749 & 0.89748 & -0.01360 & -0.02640 & -0.18573 & -0.36058 \\
\hline 30 & $\mathrm{H}$ & 0.87340 & 0.84394 & 0.91117 & -0.02946 & -0.03777 & -0.40238 & -0.51595 \\
\hline 31 & $\mathrm{H}$ & 0.87329 & 0.84323 & 0.91203 & -0.03006 & -0.03874 & -0.41064 & -0.52920 \\
\hline 32 & $\mathrm{H}$ & 0.86805 & 0.85083 & 0.89840 & -0.01722 & -0.03036 & -0.23519 & -0.41463 \\
\hline 33 & $\mathrm{C}$ & 6.53859 & 6.47041 & 6.65143 & -0.06818 & -0.11284 & -0.93125 & -1.54129 \\
\hline 34 & $\mathrm{H}$ & 0.82777 & 0.80376 & 0.85930 & -0.02400 & -0.03154 & -0.32785 & -0.43077 \\
\hline 35 & $\mathrm{H}$ & 0.83917 & 0.82006 & 0.86461 & -0.01911 & -0.02544 & -0.26103 & -0.34743 \\
\hline 36 & $\mathrm{H}$ & 0.84472 & 0.82694 & 0.86799 & -0.01778 & -0.02327 & -0.24286 & -0.31781 \\
\hline 37 & $\mathrm{H}$ & 0.86782 & 0.82844 & 0.89953 & -0.03937 & -0.03172 & -0.53782 & -0.43323 \\
\hline 38 & $\mathrm{O}$ & 8.47689 & 8.38923 & 8.53308 & -0.08766 & -0.05620 & -1.19738 & -0.76760 \\
\hline
\end{tabular}

derivatives is investigated leading to the following conclusions:

1) Through DFT calculations, a correlation between parameters related to the electronic and molecular structures of these derivatives and their ability to inhibit the corrosion process could be established.

2) The inhibition efficiency of these derivatives obtained quantum chemically increases with the increase in
$E_{\text {HомO }}$, and decrease in $E_{L U M O}$ and energy gap $\Delta E_{L-H}$. Tolyl has the highest inhibition efficiency because it had the highest HOMO energy.

3) The parameters like hardness $(\eta)$ and softness $(\sigma)$ confirm the inhibition efficiency in order of Tolyl > Inon.

4) The total energy of the best inhibitor, Tolyl, is lower than that of the Inon inhibitor, thus, the Tolyl is 
favorably adsorbed through the active center/s of adsorption on the ferrous surface.

5) A direct relationship between the inhibition efficiency and the dipole movement $(\mu)$ and the number of transferred electrons $(\Delta N)$.

6) From the local reactivity indices, Fukui function shows the nucleophilic and electrophilic attacking sites in pyrazolo [1,5-c] pyrimidine derivatives.

Finally, this study displays a good correlation between the theoretical and experimental data which confirm the reliability of the quantum chemical methods to study the inhibition of corrosion of metal surfaces.

\section{REFERENCES}

[1] N. O. Obi-Egbedi, I. B. Obot, M. I. El-khaiary, S. A. Umoren and E. E. Ebenso, "Computational Simulation and Statistical Analysis on the Relationship between Corrosion Inhibition Efficiency and Molecular Structure of Some Phenanthroline Derivatives on Mild Steel Surface,” International Journal of Electrochemical Science, Vol. 6, No. 11, 2011, p. 5649.

[2] I. B. Obot and N. O. Obi-Egbedi, "Inhibitory Effect and Adsorption Characteristics of 2,3-Diaminonaphthalene at Aluminum/Hydrochloric Acid Interface: Experimental and Theoretical Study," Surface Review and Letters, Vol. 15, No. 6, 2008, pp. 903-910. http://dx.doi.org/10.1142/S0218625X08012074

[3] H. Ju, Z.-P. Kai and Y. Li, “Aminic Nitrogen-Bearing Polydentate Schiff Base Compounds as Corrosion Inhibitors for Iron in Acidic Media: A Quantum Chemical Calculation," Corrosion Science, Vol. 50, No. 3, 2008, pp. 865-871. http://dx.doi.org/10.1016/j.corsci.2007.10.009

[4] S. A. Umoren and I. B. Obot, "Polyvinylpyrollidone and Polyacrylamide as Corrosion Inhibitors for Mild Steel in Acidic Medium,” Surface Review and Letters, Vol. 15, No. 3, 2008, pp. 277-286. http://dx.doi.org/10.1142/S0218625X08011366

[5] S. A. Umoren, I. B. Obot, E. E. Ebenso and N. O. ObiEgbedi, "Synergistic Inhibition between Naturally Occurring Exudate Gum and Halide Ions on the Corrosion of Mild Steel in Acidic Medium," International Journal of Electrochemical Science, Vol. 3, No. 9, 2008, pp. 10291043.

[6] D. Wang, S. Li, Y. Ying, M. Wang, H. Xiao and Z. Chen, "Theoretical and Experimental Studies of Structure and Inhibition Efficiency of Imidazoline Derivatives," Corrosion Science, Vol. 41, No. 10, 1999, pp. 1911-1919. http://dx.doi.org/10.1016/S0010-938X(99)00027-X

[7] H. Wang, X. Wang, H. Wang, L. Wang and A. Liu, "DFT Study of New Bipyrazole Derivatives and Their Potential Activity as Corrosion Inhibitors," Journal of Molecular Modeling, Vol. 13, No. 1, 2007, pp. 147-153. http://dx.doi.org/10.1007/s00894-006-0135-x

[8] P. Udhayakala, T. V. Rajendiran and S. Gunasekaran, "Theoretical Approach to the Corrosion Inhibition Efficiency of Some Pyrimidine Derivatives Using DFT Method," Journal of Computational Methods in Molecular De- sign, Vol. 2, No. 1, 2012, pp. 1-15.

[9] M. Finsgar, S. Fassbender, F. Nicolini and I. Milosev, "Polyethyleneimine as a Corrosion Inhibitor for ASTM 420 Stainless Steel in Near-Neutral Saline Media,” Corrosion Science, Vol. 51, No. 3, 2009, pp. 525-533. http://dx.doi.org/10.1016/j.corsci.2008.12.006

[10] S. A. Awad and K. M. Kamel, "Mechanism of CorrosionInhibition and Corrosion-Promotion of Zinc by Phosphate Ions," Journal of Electroanalytical Chemistry and Interfacial Electrochemistry, Vol. 24, No. 1, 1970, pp. 217225. http://dx.doi.org/10.1016/S0022-0728(70)80023-7

[11] S. A. Awad, K. M. Kamel, Z. Abd El-Hadi and H. A. Bayumi, "Mechanism of Anodic Dissolution of Copper in Aqueous Acidified Solutions of Different Anions," Journal of Electroanalytical Chemistry and Interfacial Electrochemistry, Vol. 199, No. 2, 1986, pp. 341-350. http://dx.doi.org/10.1016/0022-0728(86)80008-0

[12] F. M. Mahgoub, B. A. Abdel-Nabey and Y. A. El-Samadisy, "Adopting a Multipurpose Inhibitor to Control Corrosion of Ferrous Alloys in Cooling Water Systems," Materials Chemistry and Physics, Vol. 120, No. 1, 2010, pp. 104-108.

http://dx.doi.org/10.1016/j.matchemphys.2009.10.028

[13] H. Baba and T. Kodama, "Corrosion Inhibition and Characteristics of the Triazinedithiol Surface Film on Copper Under Potentiostatic Anodization,” Corrosion Science, Vol. 41, No. 10, 1999, pp. 1987-2000. http://dx.doi.org/10.1016/S0010-938X(99)00030-X

[14] T. Zhao and G. Mu, “The Adsorption and Corrosion Inhibition of Anion Surfactants on Aluminium Surface in Hydrochloric Acid,” Corrosion Science, Vol. 41, No. 10, 1999, pp. 1937-1944. http://dx.doi.org/10.1016/S0010-938X(99)00029-3

[15] M. S. Masoud, M. K. Awad, M. A. Shaker and M. M. T. El-Tahawy, "The Role of Structural Chemistry in the Inhibitive Performance of Some Aminopyrimidines on the Corrosion of Steel," Corrosion Science, Vol. 52, No. 7, 2010, pp. 2387-2396. http://dx.doi.org/10.1016/j.corsci.2010.04.011

[16] M. K. Awad, F. M. Mahgoub and M. M. El-iskandarani, "Theoretical Studies of the Effect of Structural Parameters on the Inhibition Efficiencies of Mercapto-1,2,4-triazoline Derivatives," Journal of Molecular Structure: THEOCHEM, Vol. 531, No. 1-3, 2000, pp. 105-117. http://dx.doi.org/10.1016/S0166-1280(00)00437-1

[17] M. K. Awad, "Semiempirical Investigation of the Inhibition Efficiency of Thiourea Derivatives as Corrosion Inhibitors," Journal of Electroanalytical Chemistry, Vol. 567, No. 2, 2004, pp. 219-225.

http://dx.doi.org/10.1016/j.jelechem.2003.12.028

[18] M. A. M. Ibrahim, S. S. Abd El Rehim and M. M. Hamza, "Corrosion Behavior of Some Austenitic Stainless Steels in Chloride Environments,” Materials Chemistry and Physics, Vol. 115, No. 1, 2009, pp. 80-85. http://dx.doi.org/10.1016/j.matchemphys.2008.11.016

[19] L. Feng, H. Yang and F. Wang, "Experimental and Theoretical Studies for Corrosion Inhibition of Carbon Steel by Imidazoline Derivative in $5 \% \mathrm{NaCl}$ Saturated $\mathrm{Ca}(\mathrm{OH})_{2}$ Solution,” Electrochimica Acta, Vol. 58, 2011, pp. 427 - 
436. http://dx.doi.org/10.1016/j.electacta.2011.09.063

[20] P. Hohenberg and W. Kohn, "Inhomogeneous Electron Gas,” Physical Review, Vol. 136, No. 3, 1964, pp. B864B871. http://dx.doi.org/10.1103/PhysRev.136.B864

[21] W. Kohn and L. J. Sham, "Self-Consistent Equations Including Exchange and Correlation Effects,” Physical Review, Vol. 140, No. 4, 1965, pp. A1133-A1138. http://dx.doi.org/10.1103/PhysRev.140.A1133

[22] R. G. Parr and W. Yang, "Density-Functional Theory of Atoms and Molecules," Oxford University Press, Oxford, 1989.

[23] N. I. Levine, “Quantum Chemistry,” Prentice Hall, Englewood Cliffs, 2000.

[24] W. Kohn, "Nobel Lecture: Electronic Structure of Matter -Wave Functions and Density Functionals," Reviews of Modern Physics, Vol. 71, No. 5, 1999, pp. 1253-1266. http://dx.doi.org/10.1103/RevModPhys.71.1253

[25] L. M. Rodríguez-Valdez, A. Martínez-Villafañe and D. Glossman-Mitnik, "CHIH-DFT Theoretical Study of Isomeric Thiatriazoles and Their Potential Activity as Corrosion Inhibitors," Journal of Molecular Structure: THEOCHEM, Vol. 716, No. 1-3, 2005, pp. 61-65. http://dx.doi.org/10.1016/j.theochem.2004.10.082

[26] G. K. Gece and S. Bilgiẽ, "Quantum Chemical Study of Some Cyclic Nitrogen Compounds as Corrosion Inhibitors of Steel in NaCl Media," Corrosion Science, Vol. 51, No. 8, 2009, pp. 1876-1878. http://dx.doi.org/10.1016/j.corsci.2009.04.003

[27] A. Y. Musa, A. A. H. Kadhum, A. B. Mohamad, A. A. B. Rahoma and H. Mesmari, "Electrochemical and Quantum Chemical Calculations on 4,4-Dimethyloxazolidine-2-thione as Inhibitor for Mild Steel Corrosion in Hydro-chloric Acid,” Journal of Molecular Structure, Vol. 969, No. 1-3, 2010, pp. 233-237. http://dx.doi.org/10.1016/j.molstruc.2010.02.051

[28] R. M. Issa, M. K. Awad and F. M. Atlam, "Quantum Chemical Studies on the Inhibition of Corrosion of Copper Surface by Substituted Uracils," Applied Surface Science, Vol. 255, No. 5, 2008, pp. 2433-2441. http://dx.doi.org/10.1016/j.apsusc.2008.07.155

[29] M. J. Frisch, G. W. Trucks, H. B. Schlegel, G. E. Scuseria, M. A. Robb, J. R. Cheeseman, G. Scalmani, V. Barone, B. Mennucci, G. A. Petersson, H. Nakatsuji, M. Caricato, X. Li, H. P. Hratchian, A. F. Izmaylov, J. Bloino, G. Zheng, J. L. Sonnenberg, M. Hada, M. Ehara, K. Toyota, R. Fukuda, J. Hasegawa, M. Ishida, T. Nakajima, Y. Honda, O. Kitao, H. Nakai, T. Vreven, J. A. Montgomery, Jr., J. E. Peralta, F. Ogliaro, M. Bearpark, J. J. Heyd, E. Brothers, K. N. Kudin, V. N. Staroverov, R. Kobayashi, J. Normand, K. Raghavachari, A. Rendell, J. C. Burant, S. S. Iyengar, J. Tomasi, M. Cossi, N. Rega, J. M. Millam, M. Klene, J. E. Knox, J. B. Cross, V. Bakken, C. Adamo, J. Jaramillo, R. Gomperts, R. E. Stratmann, O. Yazyev, A. J. Austin, R. Cammi, C. Pomelli, J. W. Ochterski, R. L. Martin, K. Morokuma, V. G. Zakrzewski, G. A. Voth, P. Salvador, J. J. Dannenberg, S. Dapprich, A. D. Daniels, Ö. Farkas, J. B. Foresman, J. V. Ortiz, J. Cioslowski and A. D. J. Fox, Gaussian, Inc., Wallingford, 2009, p. 09.
[30] A. D. Becke, "Density-Functional Exchange-Energy Approximation with Correct Asymptotic Behavior,” Physical Review A, Vol. 38, No. 6, 1988, pp. 3098-3100. http://dx.doi.org/10.1103/PhysRevA.38.3098

[31] C. Lee, W. Yang and R. G. Parr, "Development of the Colle-Salvetti Correlation-Energy Formula into a Functional of the Electron Density," Physical Review B, Vol. 37, No. 2, 1988, pp. 785-789. http://dx.doi.org/10.1103/PhysRevB.37.785

[32] R. G. Pearson, "Absolute Electronegativity and Hardness: Application to Inorganic Chemistry,” Inorganic Chemistry, Vol. 27, No. 4, 1988, pp. 734-740. http://dx.doi.org/10.1021/ic00277a030

[33] R. G. Parr and R. G. Pearson, "Absolute Hardness: Companion Parameter to Absolute Electronegativity,” Journal of the American Chemical Society, Vol. 105, No. 26, 1983, pp. 7512-7516. http://dx.doi.org/10.1021/ja00364a005

[34] R. G. Parr, L. V. Szentpaly and S. Liu, "Electrophilicity Index," Journal of the American Chemical Society, Vol. 121, No. 9, 1999, pp. 1922-1924. http://dx.doi.org/10.1021/ja983494x

[35] E. S. H. El Ashry, A. El Nemr, S. A. Esawy and S. Ragab, "Corrosion Inhibitors: Part II: Quantum Chemical Studies on the Corrosion Inhibitions of Steel in Acidic Medium by Some Triazole, Oxadiazole and Thiadiazole Derivatives,” Electrochimica Acta, Vol. 51, No. 19, 2006, pp. 3957-3968. http://dx.doi.org/10.1016/j.electacta.2005.11.010

[36] X. Li, S. Deng, H. Fu and T. Li, “Adsorption and Inhibition Effect of 6-Benzylaminopurine on Cold Rolled Steel in $1.0 \mathrm{M} \mathrm{HCl,"} \mathrm{Electrochimica} \mathrm{Acta,} \mathrm{Vol.} \mathrm{54,} \mathrm{No.}$ 16, 2009, pp. 4089-4098.

http://dx.doi.org/10.1016/j.electacta.2009.02.084

[37] K. R. Sandip, N. Islam and D. G. Ghosh, Journal of Quantum Information Science, Vol. 1, 2011, pp. 87-95.

[38] P. Geerlings and F. D. Proft, "Chemical Reactivity as Described by Quantum Chemical Methods,” International Journal of Molecular Sciences, Vol. 3, No. 4, 2002, pp. 276-309. http://dx.doi.org/10.3390/i3040276

[39] E. E. Ebenso, D. A. Isabirye and N. O. Eddy, “Adsorption and Quantum Chemical Studies on the Inhibition Potentials of Some Thiosemicarbazides for the Corrosion of Mild Steel in Acidic Medium," International Journal of Molecular Sciences, Vol. 11, No. 6, 2010, pp. 2473-2498. http://dx.doi.org/10.3390/ijms11062473

[40] I. Lukovits, E. Kalman and F. Zucchi, "Corrosion Inhibitors-Correlation between Electronic Structure and Efficiency,” Corrosion, Vol. 57, No. 1, 2001, pp. 3-8. http://dx.doi.org/10.5006/1.3290328

[41] E. G. Lewars, “Computational Chemistry Introduction to the Theory and Applications of Molecular and Quantum Mechanics,” Springer, London, 2011.

[42] P. Fuentealba, P. Perez and R. Contreras, "On the Condensed Fukui Function,” The Journal of Chemical Physics, Vol. 113, 2000, pp. 2544-2551. http://dx.doi.org/10.1063/1.1305879 